\title{
A Case of a Retained Needle from Insulin Pump Therapy
}

Toby Candler ${ }^{1}$, Francine Toussaint ${ }^{1}$, Susan Matthai ${ }^{2}$, Vellore AbithaKujambal ${ }^{2}=$ ${ }^{1}$ Bristol Royal Hospital for Children, ${ }^{2}$ Gloucestershire Hospitals NHS foundation Trust

\section{Background}

-Continuous Subcutaneous Insulin Infusion (CSII) therapy is increasingly used for managing children with type 1 diabetes mellitus.

- Devices vary in design by manufacturer; however in general terms insulin is administered from the pump via a subcutaneous plastic catheter or needle.

Accu-check Rapid-D Link

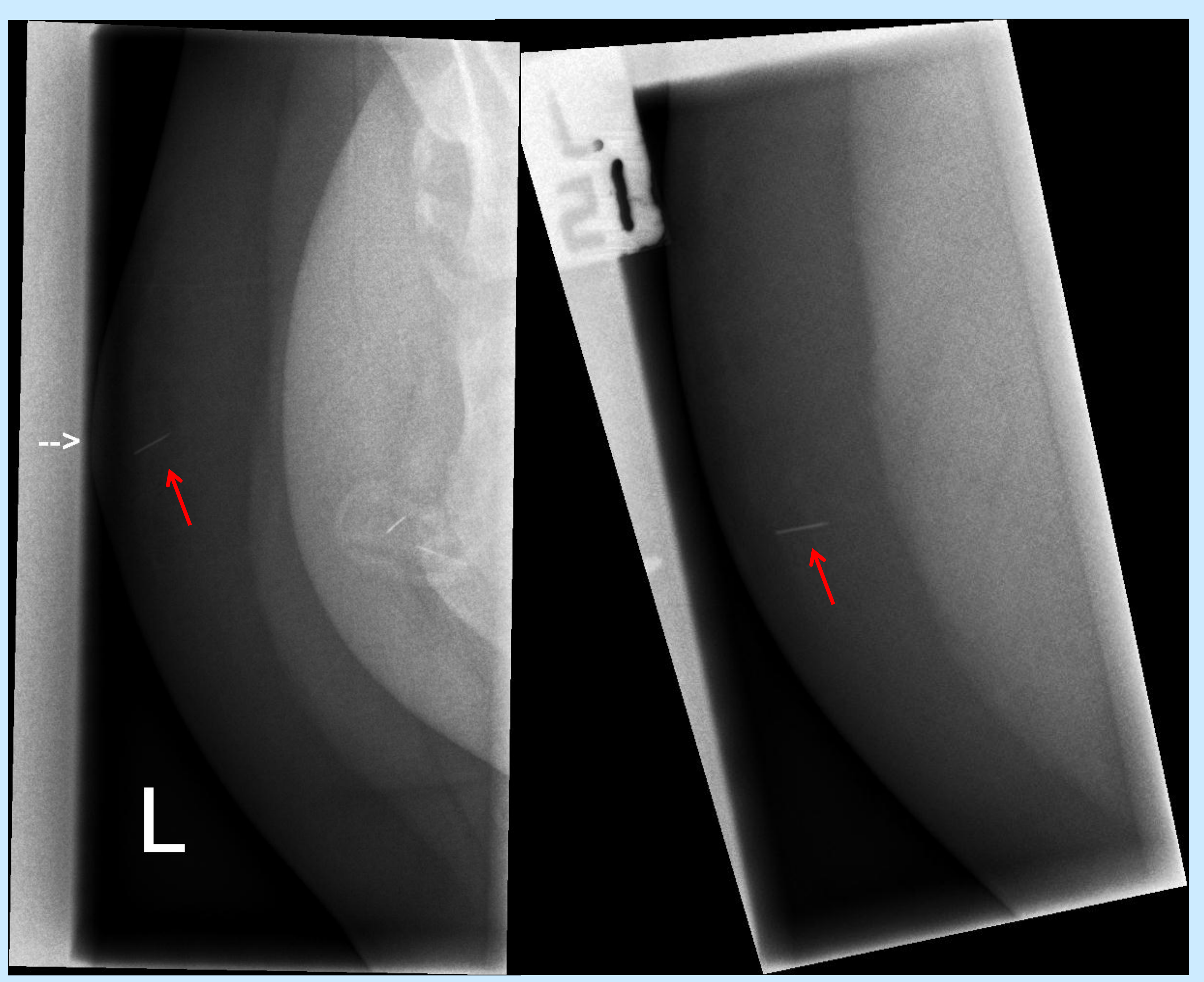

\section{Case Report}

- 5 year old boy with T1DM, well controlled with CSII (Roche Insight pump) presented with hyperglycaemia.

- His father changed the cannula and noticed when withdrawing the Rapid D cannula that the needle had detached and remained within the child's buttock and the boy complained of mild discomfort in the area.

- On examination he had localised erythema but the needle could not be palpated.

A lateral $\mathrm{x}$ ray of his buttock revealed the needle within the subcutaneous tissue.

\section{Clinical Progress}

-The needle was removed surgically under GA the following day.

-The child presented in an almost identical fashion two weeks later, with hyperglycaemia and no needle seen on withdrawal of the cannula. Again the needle could not be palpated, though was clearly seen on $\mathrm{X}$ ray, and required surgical removal

-The issues were thought to be due to a faulty batch of needles and the manufacturer was informed

\section{Discussion/Learning points}

-We present a case where, on two separate occasions, the needle became detached from the infusion device and remained in the child' s subcutaneous tissue.

-A recent published case report documented two similar cases (Plager et al, 2015) though there are no other reported cases in the medical literature.

-This is a rare complication of pump therapy but importantly highlights the risk of foreign body from the infusion system especially as devices increasingly use finer infusion set needles. 